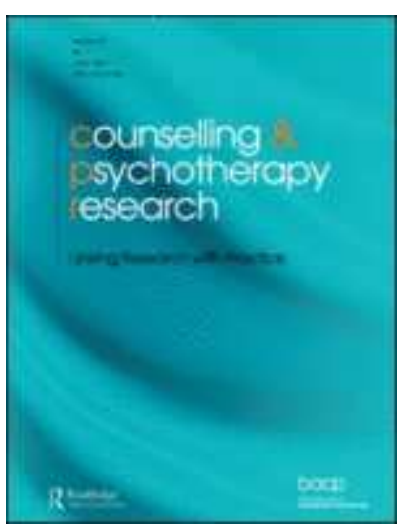

\title{
Motivation as a predictor of outcomes in school-based humanistic counselling
}

\begin{tabular}{|r|l|}
\hline Journal: & Counselling and Psychotherapy Research \\
\hline Manuscript ID: & RCPR-2010-0053.R1 \\
\hline Manuscript Type: & Original Article \\
\hline Keywords: & $\begin{array}{l}\text { school counselling, adolescent psychotherapy, motivation, client } \\
\text { centred therapy, treatment outcomes }\end{array}$ \\
\hline \multicolumn{2}{|l}{} \\
\hline
\end{tabular}

\section{SCHOLARONE}

Manuscripts 


\section{Motivation as a predictor of outcomes in school-based}

\section{humanistic counselling}

Background. Recent years have seen a growth in the provision of counselling within UK secondary schools, and research indicates that it is associated with significant reductions in psychological distress. However, little is known about the moderators and mediators of positive therapeutic benefit. In the field of adult mental health, motivation has been found to be one of the strongest predictors of therapeutic outcomes, and it was hypothesised that this may also be a predictor of outcomes for young people in school-based counselling services.

Aims. To assess the relationship between young people's motivation for counselling and its effectiveness within a secondary school setting.

Sample. Eighty-one young people (12 - 17 years old) who attended school-based humanistic counselling services in Scotland.

Method. Clients completed a measure of motivation for counselling at the commencement of their therapeutic work and a measure of psychological wellbeing at the commencement and termination of counselling.

Results. Motivation for counselling was not found to be significantly related to outcomes.

Discussion. The results indicate that the association between motivation and outcomes may be weaker in young people as compared with adults. However, a number of design factors may 
also account for the non-significant findings: insufficient participants, marginal reliability of the motivation measure and social desirability effects.

\section{Keywords}

School counselling, adolescent psychotherapy, motivation, client centred therapy, treatment outcomes. 
Recent years have witnessed a 'significant revival' of counselling services in UK secondary schools (age range: 12 -- 18 years) (Jenkins \& Polat, 2005, p. 3), with around three-quarters of schools in England and Wales claiming to provide 'therapeutic individual counselling' (Jenkins $\&$ Polat, 2005). Services have been rolled out to all secondary schools in Northern Ireland and Wales, and there is a commitment in Scotland to provide school counselling by 2015 (Public Health Institute of Scotland, 2003).

Counselling provided in these school services is predominantly of a humanistic or person-centred nature (Rogers, 1959), with young people attending for an average of 6.35 sessions (Cooper, 2009). Young people attending these services have mean levels of mental distress that are similar to those attending child and adolescent mental health units, and most commonly present with issues regarding family difficulties, anger, school problems, 'behaviour,' and relationships (Cooper, 2009).

Observational and self-report data suggest that school-based counselling services are feasible to implement and are highly acceptable to young people, pastoral care coordinators and teachers (Cooper, 2004, 2006; Cooper, Hough, \& Loynd, 2005; Pattison, et al., 2007); with a recent meta-analysis indicating a weighted effect size from pre- to post-counselling of 0.81 (Cooper, 2009). A broader review of the efficacy of person-centred and humanistic counselling for children and young people concluded that there was 'strong evidence' for the overall effectiveness of these approaches (Hölldampf, Behr, \& Crawford, 2010, p. 34).

To the present time, however, there has been very little research on the moderators and mediators of benefit in school-based counselling. Indeed, as Kazdin (2004) states, there is very little research on moderators of treatment in the child psychotherapy field as a whole. The one 
exception to this is research on the relationship between the strength of the therapeutic relationship and outcomes, where a recent meta-analysis by Shirk and Carver (2011) found a small to medium average correlation $(r)$ of.19.

This relationship between alliance and outcomes also holds in the adult psychotherapy field (Horvath \& Bedi, 2002). However, it has been argued that an even more important set of determinants of outcomes for adult clients may be 'client factors' (Asay \& Lambert, 2002; Cooper, 2008). These are qualities or characteristics that exist 'within' the person of the client (Beutler, Blatt, Alimohamed, Levy, \& Angtuaco, 2006); one of the most important of which may be clients' levels of motivation for therapy. Orlinsky, Rønnestad and Helge(2004), in their seminal review of the literature, found 14 studies in which a positive correlation was found between these motivation and outcomes, 13 in which no correlation had been found, and one in which a negative relationship had been identified. Closely connected to this, adult clients who have high levels of 'autonomous motivation' for therapy (i.e., who experience themselves as having freely chosen to enter it) tend to do better than clients who experience the impetus for therapy as coming from an external source (Seligman, 1995; Zuroff, et al., 2007). There is also a substantial body of data to suggest that an adult client's 'outcome expectancy' (Glass, Arnkoff, \& Shapiro, 2001), 'faith' (Wampold, 2001) or 'hope' (Glass, et al., 2001) in the therapeutic process is a key predictor of outcomes, with Asay and Lambert (Asay \& Lambert, 1999)estimating that it may account for as much as 15 per cent of variance in outcomes overall. Although the evidence is very limited, there is some research to suggest that these client factors may also be related to outcomes in young people. Dew and Bickman's (2005) review of the literature on expectancies suggested that client improvement was associated with positive outcome expectancies of both adults and young people referred for psychotherapy. More 
recently, Tobon, Eichstedt, Wolfeet al.(2011) found a positive correlation between levels of involvement and outcomes for children ( 8 - 12 years old) in group cognitive behavioural therapy for anxiety.

The aim of this study, therefore, was to see whether clients' motivational and attitudinal factors, known to predict outcomes in the adult psychotherapy literature, would also be predictive of outcomes in the field of youth psychotherapy and school-based counselling. Such a relationship, if found to exist, might serve an important purpose in helping to identify young people who could benefit most from counselling; and would be relevant to a wider understanding of moderating and mediating variables in child and adolescent psychological interventions.

\title{
Method
}

\section{Participants}

Data for this study came from 81 young people who, between January and July 2009, had commenced and completed an episode of counselling of more than one session in the Glasgow school-based counselling project (Cooper, 2004, 2006); and had completed both a Motivation for Counselling Questionnaire and baseline and endpoint CORE-YP forms at appropriate points in their counselling (see Figure 1).

\author{
INSERT FIGURE 1 ABOUT HERE
}


Participants came from eleven secondary schools in the Greater Glasgow area. The schools represented a range of urban, socio-economic profiles; with students of a predominantly white, Scottish ethnicity.

Forty-seven participants were female (58\%) and 34 were male (42\%). Participants were between 12 and 17 years old, with an average age of $13.68(s d=1.38)$. Participants attended, on average, 4.16 sessions of counselling $(s d=2.26$, mode $=2)$, with a mean attendance rate of $90.66 \%$. Most common reasons for referral, in descending order, were family issues (14.8\% of all clients), anger (13.6\%), stress (12.3\%), behaviour (12.3\%) and bereavement $(9.9 \%)$. Characteristics of young people in the present sample were relatively consistent with those for young people attending school counselling services across the UK (see Cooper, 2009). Data on ethnicity and physical health status of individual clients in the present sample was not available.

\section{Materials}

The Motivation for Counselling Questionnaire (MCQ) is a short, purpose-built measure designed to assess young people's motivation for, and interest in participating in, counselling. It was developed from the Attitudes to Counselling Questionnaire (Cooper, et al., 2010), which demonstrated acceptable levels of inter-item reliability (Cronbach's $\alpha=.72$ ) and test-retest reliability $(r=.71)$. The MCQ asks participants to rate the following four items on a five-point scale $(0=$ Not at all, $1=$ A little, $2=$ A moderate amount, $3=$ Quite a lot, $4=A$ lot $)$ :

- How much do you want to come to counselling?

- How much is this your choice to come to counselling? 
- Have you ever found it helpful to talk to someone when you feel sad, upset, worried or angry?

- Do you think counselling will be helpful?

Due to school timetabling constraints and time limited counselling sessions, the questionnaire aimed to be short, simple to read and easy to understand in order to be completed immediately at the start of a young person's first session of counselling.

The Young Person's CORE (YP-CORE) is a 10-item measure of emotional wellbeing for 11 to 16 year olds that has been shown to have acceptable psychometric properties and is sensitive to change (Twigg, et al., 2009). It is widely used in school-based counselling services within the UK (Cooper, 2009).

\section{Procedures}

Counsellors were instructed to invite young people to complete YP-CORE and MCQ forms at the beginning of a first counselling session, with YP-CORE forms to be completed again at the end of a final session. However, counsellors were also instructed that, if a young person was highly distressed at initial presentation, YP-CORE and MCQ forms could be completed at the commencement of a second session, and this took place in ten $(12.3 \%)$ instances.

The counselling offered to the young people was open-ended and based upon a personcentred model of practice. The basic assumption underlying this approach is that people experience psychological distress when they become estranged from their actual, underlying feelings, wants and experiences (see, Cooper, Schmid, O'Hara, \& Wyatt, 2007; Mearns \& 
Thorne, 2007; Presbury, McKee, \& Echterling, 2007; Rogers, 1959). Hence, the principal focus of the counsellor is on relating to the client in an empathic and non-judgmental way, such that the client can come to understand and appreciate themselves and their own experiences more. Given these aims, person-centred counsellors tend to work in relatively non-directive ways, with a focus on establishing a depth of relating that has the potential be challenging. Core interventions include communicating to client an empathic understanding of their experiencesand inviting them to access and express underlying emotions and needs; therebyhelping them to make sense of their experiences, behaviours and relationships (Cooper, 2009; Mearns \& Thorne, 2007).

\section{Ethical Considerations}

Ethical approval for this study was granted by The University Ethics Committee of the University of Strathclyde. The study adhered to the University of Strathclyde (2009)Code of Practice for Investigations on Human Beings, as well as the British Psychological Society (2006)Ethical Principles for conducting Research with Human Participants.

Participants were informed about the nature and purpose of the research before they agreed to take part. An information sheet was distributed highlighting confidentiality and anonymity, and young people were invited to sign a consent form if they were willing to participation in the motivation research and evaluation of the counselling. If a young person did not want to participate in the data collection it was emphasised that their counselling would not be affected in any way; completion of questionnaires was voluntary and they could withdraw at any time without explanation. In the case of any potential issues arisingupon completion of the 
questionnaire, the information sheet noted that the school counselling coordinator was available to contact.

\section{Reflexive statement}

For several years, the researchers have been interested in factors that might be associated with, and predict, improvements in school counselling. Killips and Cooper were particularly interested in the extent to which motivation might predict outcomes, and Cooper (2008) has argued that, in relation to adult counselling and psychotherapy, client factors such as motivation and involvement are key predictors of outcomes. Other members of the research team - McGinnis and Freire - did not feel that motivation, as measured in this study, would correlate significantly with positive outcomes.

\section{Analysis}

Outcomes for counselling were assessed using raw change scores from baseline to endpoint on the YP-CORE. These outcome scores were then correlated against levels of motivation, as indicated by a total motivation score on the MCQ, and against the individual motivation items. In addition, as raw change scores are compounded with baseline scores (Cohen, Cohen, West, \& Aiken, 2003), standardised residual of endpoint YP-CORE score regressed against baseline YPCORE scores were also used as an indicator of change. These outcome scores were then correlated against levels of motivation, as indicated by a total motivation score on the MCQ, and against the individual motivation items.

All analyses were conducted using SPSS Version 17. 


\section{Results}

\section{Descriptive statistics for the Motivation for Counselling Questionnaire}

Cronbach's $\alpha$ for the MCQ was of marginal sufficiency at .68. Inter-item correlations for the third item, 'Have you found it helpful to talk to someone when you feel sad, upset, worried or angry?' were less than .3 with two other items, and this item was therefore deleted from the overall scale. This left a 3-item measure with a slightly improved internal reliability of .69 and all inter-item correlations greater than .3. However, because the overall internal reliability of the measure remained marginal, the principal analysis was conducted using both a combined MCQ score for these three items, and on the individual MCQ items.

Motivation for counselling, as assessed by the three-item MCQ, was not significantly related to participants' gender, age, pre-counselling levels of psychological distress, attendance rates, or number of sessions attended. However, across the presenting issues, young people who were referred with depression had significantly lower levels of motivation (depressed $M=1.67$, non-depressed $M=2.76, F=5.88, p=.018$, Hedges' $g=-1.42$ ), while there was a trend for young people with family issues to be significantly more motivated (family issues $M=3.08$, non-family issues $M=2.66, F=3.06, p=.08$, Hedges' $g=-0.54)$.

\section{Motivation as a predictor of outcomes}

Participants' levels of motivation, as indicated by combined scores on the 3-item MCQ, were not significantly related to outcomes (see Table 1). In addition, scores on the individual motivation items were not related to outcomes. The lack of a significant relationship between motivation 
and outcomes was consistent across subgroups based on gender, age and number of session attended.

\section{INSERT TABLE 1 ABOUT HERE}

\section{Discussion}

Contrary to the adult research literature, and in contrast to the expectations of some members of the research team, young people's levels of motivation for counselling -- as assessed by a short self-report measure -was not significantly associated with outcomes.

This finding may indicate that motivation for therapy has less impact on young people's outcomes than adults. However, an alternative explanation is that motivation and outcomes are related, but that young people's levels of motivation for counselling are more fluctuating, such that initial levels at session one or two may not have been sustained throughout the work. This was the view of several of the counsellors who were involved in this study, who felt that the MCQ had been given at too early a stage for the young people to really know whether they wanted counselling or not. Although young people may have uncertainties and are reluctant to first attend counselling, once they have started the process they may already be more motivated to continue. Seligman (1995) considered that once young people are in therapy they respond better as they are more aware of what counselling involves. He also suggested that if a client is not already motivated then the therapeutic relationship will be crucial in sustaining motivation during sessions. 
A number of other explanations for this null finding should also be considered. First, it may be that the numbers of participants in this study were insufficient to detect a significant effect. Second, the MCQ may not have acted as a valid measure of motivation for counselling. The finding that, in this sample, it had marginal internal reliability would support such an explanation; as well as its lack of convergent validity with other potential indicators of client motivation, such as young people's rates of attendance at counselling sessions. Indeed, those who scored higher on the MCQ were actually more likely to cancel counselling sessions $(r=.26$, $p=.022$ ), supporting the hypothesis, as proposed above, that initial expressions of motivation for counselling may not be sustained throughout the counselling work. Moreover, while MCQ scores did not correlate with outcomes in the present sample, attendance rates did (raw change: $r$ $=.33, p=.003)$, and this suggests that motivation may be better assessed through behavioural indicators rather than through self-report. Along these lines, a third explanation for the null findings may be that young people were not able to accurately articulate their desire for counselling. They may not have been aware, for instance, of how much they wanted or did not want counselling. Closely related to this, there may have been a social desirability effect, with young people concerned to communicate to their counsellors a positive interest in counselling, which may not have reflected their real level of motivation.

Given these potential confounds, any further research on this question would benefit from a larger sample size. It would also benefit from the development of an improved measure of motivation for counselling/psychotherapy in young people; and possibly one that relied on behavioural indicators rather than self-report. If a self-report measure is used, however, it should probably have a greater number of items than the present MCQ; and also a clearer focus around the variable of motivation, rather than attempting to draw in closely related constructs, such as 
autonomous motivation and expectancy for counselling. One possibility might be to adapt a more established measure of motivation for therapy in the adult psychotherapy research field, such as the Client Motivation for Therapy Scale (Pelletier, Tuson and Haddad, 1997). For future research, it would also be beneficial if the client's responses were not seen by their counsellors, and the young people were reassured of this. Finally, future studies should assess motivation on a session-by-session basis, or at several points across therapy, such that outcomes could be more closely correlated with current levels of motivation.

An important implication of this study is that school counselling services should be wary of concentrating the delivery of service only to those students who appear motivated or keen to attend counselling. It appears, from our initial findings (and contrary to some of our expectations), that young people who are 'sent' to counselling may benefit as much from this intervention as those who actively decide to engage with it or self-refer. Whether or not this is because such young people can become motivated at a later point, or whether it is because levels of motivation and involvement are unrelated to outcome, is a question for further exploration.

\section{Summary}

The relationship between young people's self-reported motivation for school counselling and its outcome was examined, but no significant relationship was found. This may be due to greater fluctuations in young people's levels of motivation for therapy, a number of design factors in the present study, or that motivation is a weaker predictor of outcomes in counselling for adolescents than it is for adults. 


\section{References}

Asay, T. P., \& Lambert, M. J. (1999). The empirical case for the common factors in therapy: quantitative findings. In M. Hubble, B. L. Duncan \& S. D. Miller (Eds.), The Heart and Soul of Change: What Works in Therapy (pp. 33-55). Washington, DC: American Psychological Association.

Asay, T. P., \& Lambert, M. J. (2002). Therapist relational variables. In D. J. Cain \& J. Seeman (Eds.), Humanistic Psychotherapies: Handbook of Theory and Practice (pp. 531-557). Washington, DC: American Psychological Association.

Beutler, L. E., Blatt, S. J., Alimohamed, S., Levy, K. N., \& Angtuaco, L. (2006). Participant factors in treating dysphoric disorders. In L. G. Castonguay \& L. E. Beutler (Eds.), Principles of Therapeutic Change that Work (pp. 13-63). Oxford: Oxford University Press.

British Psychological Society (2006). Ethical principles for conducting research with humanparticipants. Leicester: BPS.

Cohen, J., Cohen, P., West, S. G., \& Aiken, L. S. (2003). Applied multiple regression/correlation analysis for the behavioral sciences (3rd ed.). Mahwah, NJ: Lawrence Erlbaum.

Cooper, M. (2004). Counselling in Schools Project: Evaluation Report. Glasgow: Counselling Unit, University of Strathclyde. Download from http://www.strath.ac.uk/Departments/counsunit/research/cis.html.

Cooper, M. (2006). Counselling in Schools Project Phase II: Evaluation Report. Glasgow: Counselling Unit, University of Strathclyde. Download from http://www.strath.ac.uk/Departments/counsunit/research/cis.html. 
Cooper, M. (2008). Essential Research Findings in Counselling and Psychotherapy: The Facts are Friendly. London: Sage.

Cooper, M. (2009). Counselling in UK secondary schools: A comprehensive review of audit and evaluation studies Counselling and Psychotherapy Research, 9(3), 137-150.

Cooper, M., Hough, M., \& Loynd, C. (2005). Scottish secondary school teachers' attitudes towards, and conceptualisations of, counselling. British Journal of Guidance and Counselling, 33(2), 199-211.

Cooper, M., Rowland, N., McArthur, K., Pattison, S., Cromarty, K., \& Richards, K. (2010). Randomised controlled trial of school-based humanistic counselling for emotional distress in young people: Feasibility study and preliminary indications of efficacy. Child and Adolescent Psychiatry and Mental Health, 4(1), 1-12.

Cooper, M., Schmid, P., O'Hara, M., \& Wyatt, G. (Eds.). (2007). The Handbook of PersonCentred Psychotherapy and Counselling. Basingstoke: Palgrave.

Dew, S.E. \& Bickman, L. (2005). Client Expectancies About Therapy. Mental HealthServices Research, 7(1) March 21-33.

Glass, C. R., Arnkoff, D. B., \& Shapiro, S. J. (2001). Expectations and preferences. Psychotherapy, 38(4), 455-461.

Hölldampf, D., Behr, M., \& Crawford, I. (2010). Effectiveness of person-centered and experiential therapy with children and young people: A review. In M. Cooper, J. C. Watson \& D. Hölldampf (Eds.), Person-centred and experiential therapy works: A review of the research on counselling, psychotherapy and related practices (pp. 16-44). Ross-on-Wye: PCCS. 
Horvath, A. O., \& Bedi, R. P. (2002). The alliance. In J. C. Norcross (Ed.), Psychotherapy Relationships that Work: Therapist Contributions and Responsiveness to Patients (pp. 37-69). New York: Oxford University Press.

Jenkins, P., \& Polat, F. (2005). The current provision of counselling services in secondary schools in England and Wales. Manchester: University of Manchester.

Kazdin, A. E. (2004). Psychotherapy for children and adolescents. In M. J. Lambert (Ed.), Bergin and Garfield's Handbook of Psychotherapy and Behavior Change (5th ed., pp. 543-589). Chicago: John Wiley and Sons.

Mearns, D., \& Thorne, B. (2007). Person-Centred Counselling in Action (3rd ed.). London: Sage.

Orlinsky, D. E., Rønnestad, M. H., \& Willutzki, U. (2004). Fifty years of psychotherapy processoutcome research: Continuity and change. In M. J. Lambert (Ed.), Bergin and Garfield's Handbook of Psychotherapy and Behavior Change (5th ed., pp. 307-389). Chicago: John Wiley and Sons.

Pattison, S., Rowland, N., Cromarty, K., Richards, K., Jenkins, P. L., Cooper, M., et al. (2007). Counselling in Schools: A Research Study into Services for Children and Young People in Wales. Lutterworth, Leicestershire: BACP.

Pelletier, L. G., Tuson, K. M., \& Haddad, N. K. (1997). Client Motivation for Therapy Scale: A measure of intrinsic motivation, extrinsic motivation, and amotivation for therapy. Journal of Personality Assessment, 68(2), 414-435.

Presbury, J. H., McKee, J. E., \& Echterling, L. G. (2007). Person-centered approaches. In H. T. Prout \& D. T. Brown (Eds.), Counseling and psychotherapy with children and adolescents (4th ed., pp. 180-240). Hoboken, NJ: John Wiley. 
Public Health Institute of Scotland. (2003). Needs Assessment Report on Child and Adolescent Mental Health. Edinburgh: Public Health Institute of Scotland.

Rogers, C. R. (1959). A theory of therapy, personality and interpersonal relationships as developed in the client-centered framework. In S. Koch (Ed.), Psychology: A Study of Science (Vol. 3, pp. 184-256). New York: McGraw-Hill.

Seligman, M. E. P. (1995). The effectiveness of psychotherapy - the Consumer Reports study. American Psychologist, 50(12), 965-974.

Shirk, S. R., \& Karver, M. S. (2011). Alliance in child and adolescent psychotherapy. In J. C. Norcross (Ed.), Psychotherapy Relationships that Work: Evidence-based responsiveness (2nd ed., pp. 70-91). New York: Oxford University Press.

Tobon, J.I, Eichstedt, J.A., Wolfe, V.V., Phoenix, E., Brisebois, S., Zayed, R.S. \&Harris,K.E. (2011). Group Cognitive-Behavioral Therapy for Anxiety in a Clinic Setting: Does Child Involvement Predict Outcome?Behavior Therapy, 42(2), 306-322.

Twigg, E., Barkham, M., Bewick, B. M., Mulhern, B., Connell, J., \& Cooper, M. (2009). The Young Person's CORE: Development of a brief outcome measure for young people. Counselling and Psychotherapy Research, 9(3), 160-168.

University of Strathclyde (2009). Code of practice on investigations on human beings (5th edn).Wampold, B. E. (2001). The Great Psychotherapy Debate: Models, Methods and Findings. Mahwah, NJ: Erlbaum.

Zuroff, D. C., Koestner, R., Moskowitz, D. S., McBride, C., Marshall, M., \& Bagby, R. M. (2007). Autonomous motivation for therapy: A new common factor in brief treatments for depression. Psychotherapy Research, 17(2), 137-148. 
Table 1. Correlations between levels of motivation and outcomes

\begin{tabular}{|c|c|c|c|c|}
\hline & \multicolumn{2}{|c|}{ Raw change } & \multicolumn{2}{|c|}{$\begin{array}{l}\text { Baseline.endpoint standardised } \\
\text { residual }\end{array}$} \\
\hline Measure & $r$ & $p$ & $r$ & $p$ \\
\hline Motivation (3-item MCQ) & .02 & .85 & .07 & .54 \\
\hline Item 1 . Want to come to counselling & .03 & .79 & .11 & .33 \\
\hline Item 2. Choice to come to counselling & -.03 & .77 & .03 & .79 \\
\hline Item 3. Found it helpful to talk previously & -.08 & .49 & -.01 & .93 \\
\hline Item 4. Think counselling will help & .07 & .55 & .04 & .75 \\
\hline
\end{tabular}


Figure 1: Participant flow diagram

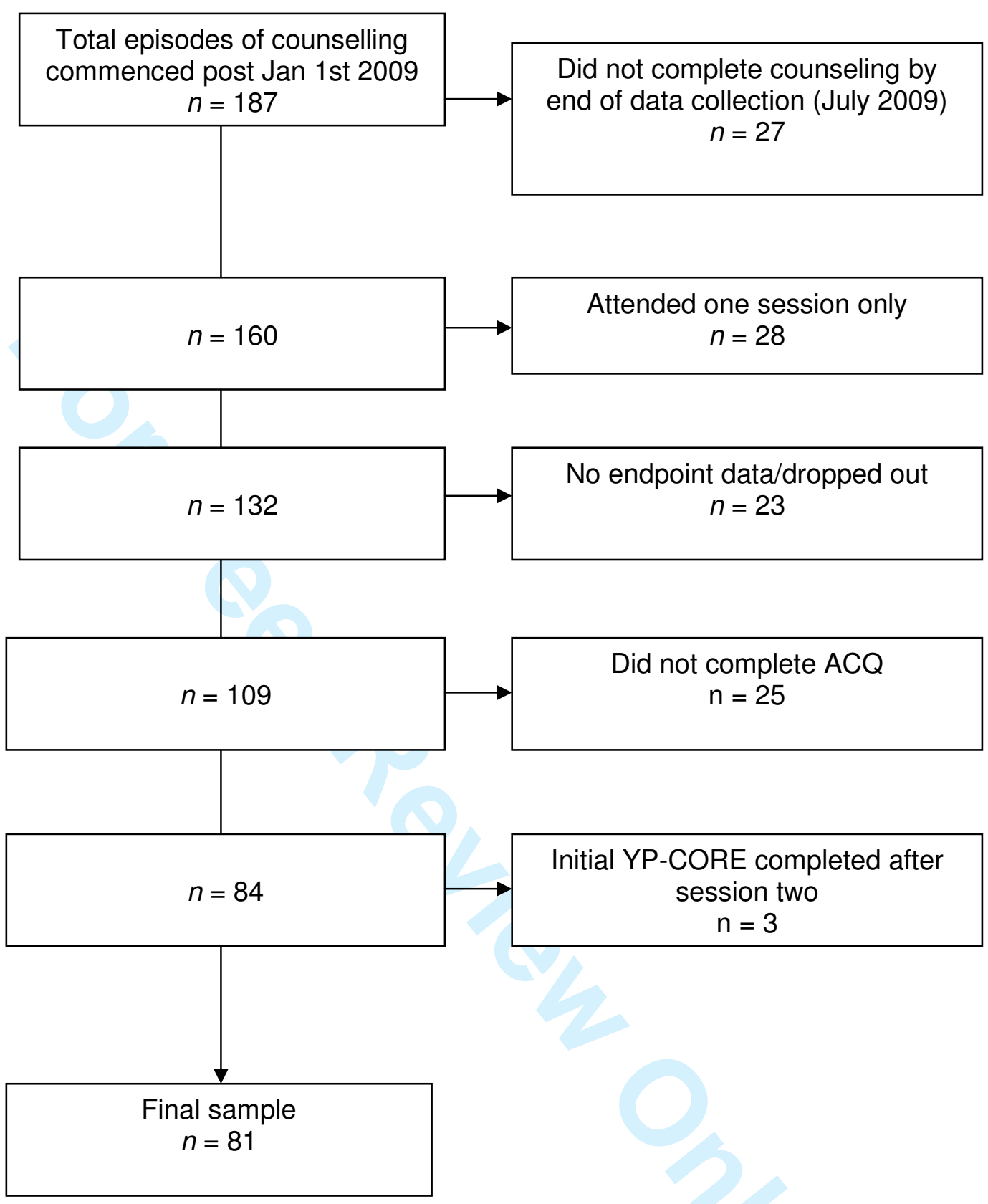

